\title{
Towards best practice in national health workforce planning
}

$\mathrm{N}$ ational health workforce planning is not a new concept. In 1995, the Australian Medical Workforce Advisory Committee (AMWAC) was established under the Australian Health Ministers' Advisory Council (AHMAC) to "assist with the development of a more strategic focus on medical workforce planning in Australia". ${ }^{1}$ In 2000, the Australian Health Workforce Advisory Committee (AHWAC) was established by AHMAC to oversee national-level, government-initiated health workforce planning in Australia, covering the nursing, midwifery and allied health workforces. Following a review of AHMAC workforce committees, AMWAC and AHWAC ceased operating in June 2006; however, at the same time, the Council of Australian Governments (COAG) agreed to a significant national health workforce reform package which included the establishment of the National Health Workforce Taskforce (NHWT). The NHWT was a time-limited entity created to develop strategies to meet the National Health Workforce Strategic Framework outcomes.

Each of these organisations carried out national health workforce planning. The importance of national workforce planning is recognised, given the challenges Australia is facing to its health workforce now and into the future. Such challenges are well documented ${ }^{2,3}$ and include an ageing population; expected increased demand for health services and increasing expectations for service delivery; changing burden of disease; and broader labour market issues. The national health reform agenda also reinforces the importance of national workforce planning. The majority of health expenditure relates to the health workforce, ${ }^{4,5}$ so any system reform subsequently has an impact on workforce. For example, many recent reforms have focused on the delivery of primary health care - the introduction of Medicare Locals, GP Superclinics and support for new roles such as nurse practitioners through enabling access to the Medicare Benefits Schedule - all of which will affect the primary care health workforce. The importance of national workforce planning was also reinforced by the National Health and Hospitals Reform Commission, which noted in 2009,

... while the Australian health system has many strengths, it is a system under growing pressure, particularly as the health needs of our population change. We face significant challenges, including large increases in demand for and expenditure on health care, unacceptable inequities in health outcomes and access to services, growing concerns about safety and quality, workforce shortages, and inefficiency. ${ }^{6}$

\section{Health Workforce Australia and national health workforce planning}

In 2008, COAG agreed to the National Partnership Agreement on Hospital and Health Workforce Reform,

\section{Summary}

- Health Workforce Australia (HWA) was established by the Council of Australian Governments through its 2008 National Partnership Agreement on Hospital and Health Workforce Reform, as the national agency to progress health workforce reform and address the challenges of providing a skilled, innovative and flexible health workforce in Australia.

- The Australian Health Ministers' Conference commissioned HWA to undertake a workforce planning exercise for doctors, nurses and midwives over a planning horizon to 2025.

Health Workforce 2025 (HW 2025) was conducted in two phases: developing projections for the size and type of the health workforce (doctors, nurses and midwives) needed to meet future service requirements from 2012 to 2025; and modelling the training pipeline necessary to meet the size and type of this health workforce.

- HWA has used a number of key principles in developing HW 2025 to ensure the projections are robust and able to be applied nationally.

- HW 2025 is not a one-off project. Projections will be updated as new data become available, and methodology and assumptions underpinning the projections will be periodically reviewed.

- To also ensure the continued improvement of national health workforce planning, HWA is pursuing other areas for improvement, including better national data collections and improved estimation methodology for demand.

- Results of HW 2025 were presented to the Australian Health Ministers (through the Standing Council on Health) in April 2012.

which acknowledged that a national, coordinated approach to health workforce reform with a particular focus on linking efforts of health and higher education sectors was necessary. Subsequently, Health Workforce Australia (HWA) was established as the national agency to progress health workforce reform in Australia and address the challenges of providing a skilled, innovative and flexible health workforce. HWA is a Commonwealth statutory authority, the HWA Board is its governing body, and HWA reports to the Standing Council on Health (SCoH, previously the Australian Health Ministers' Conference).

The Australian Health Ministers' Conference commissioned HWA to undertake a workforce planning exercise for doctors, nurses and midwives over a planning horizon to 2025. This project was to present (and measure) possible future health workforce outcomes and training implications under a range of workforce planning scenarios. It was initially known as the National Training 
Plan; however, in recognition of the fact the planning scenarios identify a range of future health workforce outcomes arising from various potential policy options, of which training is only one, the report has been renamed Health Workforce 2025 - Doctors, Nurses and Midwives (HW 2025). HW 2025 was conducted in two phases. Phase 1 developed projections for the size and type of the health workforce (doctors, nurses and midwives) needed to meet future service requirements from 2012 to 2025 under a range of alternative "futures", including:

- moving to self-sufficiency (demonstrated by modelling reducing overseas migration);

- productivity gains over the projection period;

- capped working hours for doctors; and

- changing nursing retention rates.

Phase 2 modelled the training pipeline necessary to meet the size and type of the health workforce identified in phase 1. That is, it provides the estimated numbers of professional entry students, graduates and trainees (for doctors) required between 2012 and 2025 to achieve a workforce in balance at the end of the planning period. Results of HW 2025 were presented to the Australian Health Ministers through the SCoH in April 2012.

In developing HW 2025, HWA followed a number of key principles to ensure the projections are robust, realistic, sophisticated and able to be applied nationally.

\section{Key principles}

\section{Authoritative national planning approach}

While all states and territories have conducted health workforce planning, such planning is for their own specific purposes and is conducted using different datasets, assumptions and methodologies. This means the projections developed are generally not comparable or able to be aggregated to present a national picture. HW 2025 has been developed to be able to provide this authoritative national approach with its use of a consistent methodology and national data.

\section{Methodological robustness and coherence}

Development of the modelling technique employed in HW 2025 involved consideration of a broad range of literature relating to health workforce planning and modelling. The principal method chosen was simulation modelling using a stock and flow approach, together with scenario analysis. The supply modelling tool uses a dynamic version of the stock and flow approach, while demand modelling is based on applying service utilisation rates for 5-year age and sex cohorts together with population projections to derive the rate of change in demand over the projection period. For midwifery, birth rates together with utilisation data were used to calculate demand. ${ }^{7}$

The same methodology and modelling tools were applied across the doctor, nursing and midwifery workforces to generate the projections. This consistency and coherence in application therefore allows for meaningful comparisons and policy considerations at a national level.

\section{Use of national data}

The use of consistent methodology and modelling tools was supported by the use of national datasets. All input data were sourced from nationally comparable datasets. This means the characteristics of the existing workforces and derived items such as exit rates were all developed on the same basis across Australia. While other data sources may exist that provide greater detail or accuracy, such sources only cover individual sectors, states or territories and they could not easily be used for national modelling. The use of national data therefore reinforces the coherence and consistency of applying the same methodology across workforces to allow for meaningful national comparisons. A list of the key datasets used in HW 2025 is provided in the Box.

\section{Explicit assumptions}

Projections provide likely outcomes depending on the assumptions on which they are based. If any of the assumptions are not applicable, or cease to reflect realworld situations, the projections will not provide an accurate indication of future outcomes. To ensure the assumptions underpinning HW 2025 modelling were realistic and defensible, they were exposed for critical review through an extensive consultative process. The underpinning assumptions are also available with the publication of the projections to ensure the results can be interpreted accurately. In recognition of changing circumstances that may have an impact on the assumptions made in the initial version of HW 2025, the underpinning assumptions will be reviewed regularly to ensure their ongoing relevance.

\section{Consultation and review processes}

HW 2025 projections are generated from the methodology, data and assumptions used. To ensure the relevance of the projections to the doctor, nursing and midwifery workforces, these three aspects were consulted on extensively in the development of HW 2025. In particular: - A Technical Reference Group composed of representatives from academia, government and the health sector was created to provide advice and expertise on issues including the appropriateness of the modelling assumptions and best-practice approaches to quantifying education and training capacity and modelling workload measures.

- The methodology paper was available for public comment. $^{7}$

- Structured workshops were conducted with workforce participants and organisations to expose the overall method and the assumptions underlying the baseline projections to critical review.

- Clinical leads (health professionals representing each of the fields of medicine, nursing and midwifery) provided clinical expertise and context to modelling and pipeline analysis and the development of alternative scenarios.

- Clinical Advisory Groups were established to develop and test the assumptions underlying phase 2 pipeline projections. 


\begin{tabular}{|c|c|}
\hline Workforce group & Data source \\
\hline \multicolumn{2}{|l|}{ Doctors } \\
\hline $\begin{array}{l}\text { Workforce headcount } \\
\text { and demographics }\end{array}$ & AlHW Medical Labour Force Survey \\
\hline Graduates & $\begin{array}{l}\text { Medical Deans Australia and New } \\
\text { Zealand }\end{array}$ \\
\hline Fellows & Medical colleges \\
\hline Immigration & $\begin{array}{l}\text { Department of Immigration and } \\
\text { Citizenship }\end{array}$ \\
\hline \multirow[t]{3}{*}{ Demand } & Hospital separation statistics \\
\hline & Medicare utilisation statistics \\
\hline & $\begin{array}{l}\text { Australian and New Zealand } \\
\text { Intensive Care Society }\end{array}$ \\
\hline \multicolumn{2}{|l|}{ Nurses } \\
\hline $\begin{array}{l}\text { Workforce headcount } \\
\text { and demographics }\end{array}$ & $\begin{array}{l}\text { AlHW Nursing and Midwifery Labour } \\
\text { Force Survey }\end{array}$ \\
\hline Graduates & $\begin{array}{l}\text { Department of Employment, } \\
\text { Education and Training } \\
\text { (for registered nurses) and NCVER } \\
\text { (for enrolled nurses) }\end{array}$ \\
\hline Immigration & $\begin{array}{l}\text { Department of Immigration and } \\
\text { Citizenship }\end{array}$ \\
\hline \multirow[t]{4}{*}{ Demand } & Hospital separation statistics \\
\hline & Community care places \\
\hline & Residential high-care places \\
\hline & $\begin{array}{l}\text { Australian and New Zealand } \\
\text { Intensive Care Society }\end{array}$ \\
\hline \multicolumn{2}{|l|}{ Midwives } \\
\hline $\begin{array}{l}\text { Workforce headcount } \\
\text { and demographics }\end{array}$ & $\begin{array}{l}\text { AlHW Nursing and Midwifery Labour } \\
\text { Force Survey }\end{array}$ \\
\hline Graduates & $\begin{array}{l}\text { Department of Employment, } \\
\text { Education and Training }\end{array}$ \\
\hline Immigration & $\begin{array}{l}\text { Department of Immigration and } \\
\text { Citizenship }\end{array}$ \\
\hline \multirow[t]{2}{*}{ Demand } & $\begin{array}{l}\text { ABS Births Australia (ABS Cat. No. } \\
3301.0 \text { ) }\end{array}$ \\
\hline & $\begin{array}{l}\text { ABS Australian population } \\
\text { projections series B }\end{array}$ \\
\hline
\end{tabular}

AlHW = Australian Institute of Health and Welfare. NCVER = National Centre for Vocational Education Research. ABS = Australian Bureau of Statistics.

- A Geographical Distribution Expert Reference Group was created to provide expert advice on regional distribution issues.

The engagement and input of these groups was vital in ensuring HW 2025 generated realistic and useful projections.

\section{Scenario and sensitivity analysis}

Sensitivity analysis allows understanding of which variables and assumptions have the most significant impact on the overall modelling results. The scenario modelling used by HW 2025 allows alternative futures to be modelled by varying input parameters. There are two purposes of the alternative scenarios:

- To explore the implications of possible alternative futures.
- To demonstrate the sensitivity of the model to various input parameters.

By altering parameters in the model, the flow-through effect to the future workforce can be measured through the impact relative to the comparison scenario. The comparison scenario is a technical construct for modelling purposes, generated to enable the evaluation of the impact that planning scenarios may have on the medical, nursing and midwifery workforces. It should be interpreted as a "do nothing" scenario in which the conditions in 2009 are projected into the future without significant change. In modelling the alternative scenarios, the variables that respond with the most significant change demonstrate the sensitivity of the model to that parameter. This can assist in highlighting which datasets should be a future priority in terms of improving data availability and quality as well as guiding the formulation of other alternative scenarios.

\section{An iterative process}

In any modelling, projections become less accurate as the period of time over which they apply increases. This is owing to many factors, including error in projection methodologies, changes in service delivery (eg, technological change) that impact on the relationship between the type and number of services provided, and changes in data and assumptions used in the projections. The World Health Organization noted:

It is therefore critical that plans include mechanisms for adjustment according to changing ongoing circumstances. Making projections is a policy-making necessity, but is also one that must be accompanied by regular re-evaluation and adjustment. ${ }^{8}$

In recognition of this, HW 2025 is not a one-off project. Projections will be updated annually as new data become available, and the methodology and assumptions will be periodically reviewed with the assistance of clinical experts, to ensure the projections remain realistic and relevant.

\section{Looking forward}

One of the key principles underpinning HW 2025 is that it will be an ongoing process in which projections will be continually improved. There are several factors that will be pursued with the aim of improving HW 2025 projections.

\section{Data collection}

Modelling relies on the data from which the model's parameter inputs and base workforce are derived. HW 2025 uses national datasets, the availability of which for the health workforce is limited. In the initial iteration of HW 2025, considerable reliance has been placed on the medical labour force surveys and nursing and midwifery labour force surveys undertaken by the Australian Institute of Health and Welfare. A key future direction is to improve the quality of existing national datasets and identify additional datasets that can be used. In particular, future iterations of HW 2025 are expected to use labour force data from the national registration and accreditation scheme, administered by the Australian Health Practitioner Regulation Agency. A piece of infrastructure being developed by HWA that will support this direction is the 
National Health Workforce Statistical Resource, incorporating the National Health Workforce Dataset. This will provide a repository of data and integrated tools to assist in health workforce planning by all levels of government and other organisations, as well as by HWA.

\section{Alternative demand measures}

The demand for health professionals can vary as a function of changes in population characteristics, changes to expectations of care, new models of care, or workplace changes due to workforce reform that result in an increase or decrease in the relative requirement for certain professions. HWA is currently investigating demand measurement methods that could be used as an alternative to current utilisation.

\section{Consideration of skills or competency-based planning}

In Australia, it is recognised that in addition to this form of traditional workforce planning methodology, there is a need to enable planning for the health roles and models of service delivery that will best meet the needs of consumers and be responsive to regional planning requirements. ${ }^{9}$ In addition to workforce planning, HWA has a focus on workforce innovation and reform to encourage the development of health workforce models to support new models of health care delivery. The workforce modelling tool developed as part of HW 2025 will be able to test and evaluate the likely impact of reform predictions and theories.

\section{Expanding the scope of HW 2025}

In 2012, the scope of HW 2025 has expanded to include dentistry and a number of selected allied health professions. This is in addition to the projections for doctors, nurses and midwives being updated as new data become available.

\section{Conclusion}

There is an ongoing need for health workforce planning to meet the challenges the Australian health workforce is facing now and in the future. Health workforce projections provide a tool to enable planning by highlighting areas of potential workforce imbalance that may call for government intervention or reform. While health workforce projections have been generated at national and state and territory levels previously, this was often done using different datasets, assumptions and methodologies, making it difficult to provide a nationally coherent view of the future health workforce. Through HW 2025, HWA is developing a set of nationally authoritative, consistent and coherent health workforce projections that can be used for health workforce planning. In particular, the iterative nature of HW 2025 provides a means for planners to monitor the impact of incremental adjustments to the health workforce, taking account of significant changes in the health system or underlying social and economic environment.

Competing interests: No relevant disclosures.

Provenance: Commissioned; externally peer reviewed.

1 Australian Medical Workforce Advisory Committee. Medical workforce planning in Australia. Aust Health Rev 2000; 23: 8-26.

2 Australian Government Productivity Commission. Australia's health workforce. Research report. Canberra: Commonwealth of Australia, 2005. http://www.pc.gov.au/projects/study/healthworkforce/docs/ finalreport (accessed Mar 2012).

3 The Treasury. Intergenerational report 2010. Australia to 2050: future challenges. Canberra: Commonwealth of Australia, 2010. http:// archive.treasury.gov.au/igr/igr2010/default.asp (accessed Mar 2012).

4 Hernandez P, Dräger S, Evans DB, et al. Measuring expenditure for the health workforce: evidence and challenges. Geneva: World Health Organization, 2006. http://www.who.int/hrh/documents/measuring_ expenditure.pdf (accessed May 2012).

5 Australian Institute of Health and Welfare. Australian hospital statistics 2009-10. Canberra: AlHW, 2011. (AlHW Cat. No. HSE 107; Health Services Series No. 40.) http://www.aihw.gov.au/publicationdetail/?id=10737418863 (accessed May 2012).

6 National Health and Hospitals Reform Commission. A healthier future for all Australians: National Health and Hospitals Reform Commission - Final report June 2009. Canberra: Commonwealth of Australia, 2009. http://www.health.gov.au/internet/main/publishing.nsf/Content/ nhhrc-report (accessed Mar 2012).

7 Health Workforce Australia. National training plan - methodology paper. Adelaide: HWA, 201l. http://www.hwa.gov.au/sites/uploads/ national-training-plan-methodology-paper-05-2011.pdf (accessed May 2012).

8 World Health Organization. Models and tools for health workforce planning and projections. Human Resources for Health Observer, 3. Geneva: WHO, 2010. http://whqlibdoc.who.int/publications/2010/ 9789241599016_eng.pdf (accessed Mar 2012).

9 Health Workforce Australia. National health workforce innovation and reform strategic framework for action 2011-2015. Adelaide: HWA, 201l. https://www.hwa.gov.au/sites/uploads/hwa-wir-strategicframework-for-action-201110.pdf (accessed Mar 2012). 